\title{
Interdisciplinaridade no enfoque intersubjetivo habermasiano: reflexões sobre planejamento e AIDS
}

\author{
Interdisciplinarity from intersubjectivity \\ habermasian approach: reflections about \\ planning and AIDS
}

\footnotetext{
1 Departamento

de Administração

e Planejamento, Escola

Nacional de Saúde Pública,

Fundação Oswaldo Cruz.

Rua Leopoldo Bulhões,

1.480/70 andar -

21041-210 - Manguinhos -

Rio de Janeiro, RJ

artmann@ensp.fiocruz.br
}

Abstract This paper is aimed to discuss interdisciplinarity from Habermas approach, which importance is due to the possibility of a wider and integrated view of different rationalities within health field. Some basic concepts from the habermasian paradigm are presented in order to explore the possibility of an interdisciplinarity project in health field. Special emphasis is given to the role of language as an articulator of the action in general and all the knowledge related to the action or performance in the world. Concepts from the Strategic-Situational Planing approach are also taken as reference to discuss and an example of the problem of an increase of AIDS incidence, from the point of view interdisciplinary from the Health Department's perspective in a medium size municipality.

Key words Interdisciplinarity and intersubjectivity, Interdisciplinarity and health
Resumo Este artigo se propõe a discutir a interdisciplinaridade na perspectiva de Habermas por ser este enfoque considerado relevante e bastante promissor para a área da saúde, na medida em que permite uma abordagem mais ampla e ao mesmo tempo integradora das diversas racionalidades/especializações que perpassam este objeto tão complexo. São apresentados alguns conceitos básicos do paradigma habermasiano para discutir a possibilidade de construção de um projeto interdisciplinar na área da saúde, destacando o papel assumido pela linguagem na qualidade de articuladora da ação em geral e de todas as formas de saber ligadas à atuação sobre o mundo, considerado em seu conceito tríplice ampliado e em relação ao mundo vital. Nesta discussão toma-se, ainda, como referência, conceitos do Planejamento Estratégico Situacional e o exemplo do processamento parcial de um problema de aumento de incidência da AIDS a partir do olhar da secretaria de saúde de um município de médio porte.

Palavras-chave Interdisciplinaridade e intersubjetividade, Interdisciplinaridade e saúde 


\section{Introdução}

Assiste-se hoje a duas tendências a princípio contraditórias. Por um lado, a uma cada vez maior especialização e conseqüente fragmentação do saber que se expressa na multiplicação de disciplinas nas universidades e centros de pesquisa e nas explicações sempre mais especializadas e parciais sobre a realidade.

Por outro lado, o reconhecimento de cientistas, pesquisadores, intelectuais e profissionais das mais diversas áreas sobre a necessidade de atravessar as estreitas fronteiras disciplinares e construir um diálogo interdisciplinar como forma de superar os efeitos negativos dessa fragmentação é crescente e inegável. A necessidade de intervenções concretas diante dos problemas da sociedade, sejam eles relacionados a questões econômicas, sociais, culturais, setoriais (saúde, educação), tecnológicas, de organização da vida urbana ou rural ou aqueles relacionados a questões éticas e de sobrevivência da espécie conduz ao questionamento sobre a capacidade das disciplinas isoladas ou saberes compartimentalizados fornecerem tais respostas.

A área da saúde não foge a esse diagnóstico e expressa em seu interior estas mesmas tendências, ainda de forma mais contundente, pela própria complexidade de seu objeto, que necessariamente precisa ser abordado de forma interdisciplinar. Nem é necessário nos alongarmos nessa questão na medida em que tantos autores o reconhecem. Cecília Minayo (1991) sintetiza bem esta complexidade: $\mathrm{Ne}$ nhuma disciplina por si só dá conta do objeto a que perseguimos, porque ele envolve ao mesmo tempo e concomitantemente as relações sociais e o social propriamente dito, as expressões emocionais e afetivas assim como o biológico que, em última instância, traduz, através da saúde e da doença, as condições e razões sociohistóricas e culturais de indivíduos e grupos. Nunes (1995), ao resgatar as origens gregas da palavra saúde como inteiro, intacto, integridade, afirma que esta não permite a fragmentação em saúde física, mental e social, devendo partirse de uma visão holística que supõe compreendê-la na interface de uma grande diversidade de disciplinas, o que se torna ainda mais complexo quando se passa para a esfera da saúde coletiva.

A importância sobre o tema da interdisciplinaridade destacada por Nunes (1995), a apresentação de seu desenvolvimento através da história e o amplo resgate das discussões, movimentos e eventos mais recentes sobre a interdisciplinaridade na área da saúde realizado por este autor nos eximem dessa tarefa. Podemos, portanto, ir diretamente ao tema.

Nos propomos, neste trabalho, a debater a interdisciplinaridade a partir do enfoque habermasiano porque o consideramos bastante promissor para a área da saúde, na medida em que permite uma abordagem mais ampla e ao mesmo tempo integradora das diversas racionalidades/especializações que perpassam esse objeto tão complexo.

Apresentamos alguns conceitos básicos do paradigma habermasiano para discutir a possibilidade da construção de um projeto interdisciplinar na área da saúde, destacando o papel assumido pela linguagem como articuladora da ação em geral e de todas as formas de saber ligadas à atuação sobre o mundo considerado em seu conceito tríplice ampliado e em relação ao mundo vital. Nesta discussão tomamos como referência conceitos do Planejamento Estratégico Situacional, e o exemplo do processamento parcial de um problema de aumento da incidência da AIDS a partir do olhar da secretaria de saúde de um município de médio porte.

\section{Alguns conceitos para entender Habermas}

- Conceito tríplice de mundo - Popper (1975) distingue três regiões num único mundo. Habermas (1987) constrói, a partir da proposição popperiana, um conceito tríplice de mundo preferindo, contudo, manter três mundos distintos. Assim, temos o mundo objetivo o qual se refere ao mundo físico ou aos estados de coisas existentes; o mundo social ou normativo relacionado às normas sociais e culturais sob as quais agimos e o mundo subjetivo que se refere ao mundo interno dos indivíduos.

- Conceito de mundo da vida e sistema - O mundo da vida é constituído pela cultura, pela sociedade e pela personalidade. A cultura armazena conhecimentos e tradições historicamente construídas pelas gerações anteriores, a sociedade nos fornece o contexto normativo sob o qual agimos e é na personalidade onde se encontram as competências individuais para a comunicação. Essas três dimensões articuladas pela linguagem que é também constitutiva do mundo da vida nos fornecem 
o "pano de fundo" das pré-interpretações e saberes implícitos que orientam nossas ações (Herrero, 1987). Esse conceito, embora apoiado na fenomenologia de Husserl e Schutz, se diferencia porque Habermas o alarga para além do horizonte da consciência dos sujeitos e concebe-o a partir da relação intersubjetiva entre sujeitos que falam e agem visando coordenar cooperativamente seus planos de ação (Siebeneichler, 1989a).

Para Habermas existe uma dialética entre o mundo da vida (mediado pela linguagem), representado pela cultura e pela razão comunicativa e o sistema (mediado pelo poder e pelo dinheiro), representado pela razão técnica, instrumental. Em seu diagnóstico da sociedade contemporânea, refere-se a um avanço da racionalidade técnica ou do sistema sobre o mundo da vida. Através de uma crítica hermenêutica seria possível, segundo o autor, desvendar formas distorcidas de comunicação e buscar uma reconciliação entre o mundo da vida e o sistema.

- Teoria da ação comunicativa - Um dos pontos de partida da teoria habermasiana é a crítica à teoria da ação de Weber. Para Habermas, a teoria weberiana reduz a ação a uma dimensão instrumental/teleológica ou estratégica que corresponde a uma forma de conhecimento e intervenção sobre estados de coisas do mundo objetivo, onde o critério de validade da ação estaria representado pela verdade ou pela eficácia da intervenção sobre o mundo. Essa forma de ação se transforma em estratégica quando envolve outros atores sobre os quais se pretende influenciar. Neste caso, os outros atores são reificados e vistos como meios ou obstáculos a superar.

Para Habermas, o conceito de racionalidade da ação pressupõe, além do tipo de ação teleológica ou estratégica, que se refere apenas ao mundo objetivo, mais três tipos de ação:

1) Ação normativa: voltada para a produção e legitimação de normas sociais. Relaciona-se pelo menos com dois mundos: o mundo objetivo e o normativo.

2) Ação expressiva: que representa um tipo de ação voltada para a comunicação e reconhecimento da autenticidade de estados internos ou subjetivos dos indivíduos. Pressupõe relações com um mundo externo e um mundo interno.

3) Ação comunicativa: construído a partir da filosofia da linguagem de Austin e Searle, o conceito de ação comunicativa corresponde a uma relação intersubjetiva mediada lingüisticamente onde são levantadas pretensões de validade (enunciados) que se candidatam a serem aceitos ou não pelos interlocutores. Apoiadas no tríplice conceito de mundo, as pretensões de validade se referem tanto a estados de coisas do mundo objetivo, a normas do mundo social e a expressões do mundo subjetivo. Isso significa que somente a ação comunicativa pressupõe o uso da linguagem em todas as suas dimensões, estando referida ao mesmo tempo aos três mundos, articulados pelo mundo da vida - o equivalente ao saber prévio ou conjunto de pretensões de validade cristalizadas como acordo ou consenso, que se expressam como saber teórico, prático ou expressivo.

Toda ação implica um saber prévio ou conjunto de pressuposições que orienta o conhecimento de situações e a atuação sobre as mesmas. Ou seja, conhecemos o mundo ou atuamos sobre ele a partir do "pano de fundo" de um mundo da vida predeterminado. Essa aproximação a um mundo descentralizado, alargado, pode ser a-crítica, como reprodução natural desses conteúdos prévios, ou crítica, como revisão de conteúdos pouco funcionais às novas situações.

De qualquer forma, toda ação implica um saber prévio na precedência da linguagem. Por isso, para o autor, a ação comunicativa está na base de todas as outras formas. A linguagem é uma forma de ação, pois pelo seu componente performativo (tipo de relação intersubjetiva implícita) constitui-se numa maneira de relacionar-se intersubjetivamente com o(s) mundo(s) que desencadeia outros tipos de ação. Constatar algo é diferente de prometer fazer algo ou de pedir que alguém faça algo. São três vínculos intersubjetivos distintos que correspondem a componentes performativos diferenciados da linguagem: constatação, promessa, ordem, que supõem orientações distintas em relação ao mundo. Constatar é típico do mundo objetivo. $\mathrm{O}$ ato de fala chamado de petição reivindica a legitimidade da norma para ser cumprida, articulando uma dimensão do mundo social. O nível da constatação ou da petição antecipam outras ações finalísticas.

É importante destacar que a construção do conceito de ação comunicativa pressupõe uma mudança do paradigma da consciência ou da filosofia do sujeito para o paradigma da comunicação ou da intersubjetividade.

- O paradigma da comunicação - Neste novo paradigma, conhecer e atuar sobre o mun- 
do não representa mais uma ação solitária de um ator ou sujeito que quer conhecer e agir sobre objetos, mas uma relação intersubjetiva lingüisticamente mediada onde o sujeito, além do interesse em conhecer e atuar sobre o mundo, está interessado em entender-se junto com outros sujeitos sobre o significado das questões a respeito do conhecer e agir sobre objetos no mundo. Nesse paradigma, o fundamental não é o enfoque objetivante, mas o enfoque performativo do entendimento intersubjetivo entre sujeitos capazes de falar e atuar. Habermas trabalha essa questão a partir dos enunciados performativos de Austin e do conceito de comunidade comunicacional de Apel.

Do ponto de vista da razão, a diferença entre o paradigma do sujeito e o paradigma da comunicação pode ser explicitada como a seguir descrito (Siebeneichler, 1989). Para a razão centrada no sujeito, valem os critérios de verdade no conhecimento de objetos e de sucesso no domínio sobre objetos e coisas. Esses dois critérios mediam as relações entre o sujeito e o mundo.

A razão centrada na comunicação busca sua validação em procedimentos argumentativos que procuram resgatar direta ou indiretamente três tipos de pretensões de validade: de verdade proposicional referida ao mundo objetivo; de correção normativa, referente ao mundo social e de autenticidade subjetiva. O conceito de razão passa a ser processual e comunicativo, deduzido de uma lógica pragmática da argumentação. Inclui, portanto, além do elemento cognitivo e instrumental, elementos relacionados à moral, à pratica, à emancipação e à estética.

O primeiro caso, para Habermas, configura uma distorção na medida em que uma determinada relação (a teleológica ou a estratégica) real e necessária, porém, que deveria estar subordinada à comunicativa, toma o lugar do todo, sem possuir, contudo, estrutura para tal, pois os critérios de validação para o mundo objetivo não servem para os demais mundos.

O paradigma comunicativo rompe com a velha moldura da relação sujeito/objeto substituindo-a por uma relação intersubjetiva onde se emitem e resgatam pretensões de validade sobre coisas do mundo objetivo, sobre normas ou expectativas de comportamento geral do mundo social e sobre estados subjetivos. Esta aproximação ao mundo deixa de ter exclusivamente a marca da dominação ou o con- trole de um sujeito sobre um objeto a ser conhecido ou manipulado e passa a representar uma construção solidária em que os atores se entendem sobre a melhor forma de atuar.

\section{Construindo a interdisciplinaridade}

Japiassu (1976) define a disciplinaridade como um conjunto sistemático e organizado de conhecimentos com características próprias nas distintas áreas de ensino, método etc., cuja exploração conduz a novos conhecimentos que substituem os antigos. Discute as diferentes nuances das relações interdisciplinares através dos termos "multi", "pluri", "inter" e transdisciplinaridade. Siebeneichler (1989b) agrupa essas formas de relações em dois grupos básicos: no primeiro, encontram-se a multi e pluridisciplinaridade e no segundo, a inter e transdisciplinaridade. A seguir, destacamos brevemente cada um dos conceitos.

Multidisciplinaridade: refere-se basicamente a uma associação ou justaposição de disciplinas que abordam um mesmo objeto a partir de distintos pontos de vista. É comum em congressos e seminários, onde vários especialistas se encontram para discutir um objeto sob diversos ângulos. Contudo, não se verifica uma integração interdisciplinar.

Pluridisciplinaridade: aqui avança-se um pouco e se estabelecem algumas relações entre disciplinas. Como exemplo poderíamos pensar o diagnóstico de saúde de uma comunidade onde trabalham epidemiologistas, estatísticos e assistentes sociais.

Interdisciplinaridade: busca-se a superação das fronteiras disciplinares. Pode-se construí-la através da definição do que as disciplinas científicas têm em comum em níveis de integração mais profundos, através da unificação ou síntese de conhecimentos científicos ou do estabelecimento de uma linguagem interdisciplinar consensualmente construída entre os cientistas. Observa-se uma troca profunda entre disciplinas, onde instrumentos, métodos e esquemas conceituais podem vir a ser integrados.

Transdisciplinaridade: segundo Piaget, citado por Nunes (1995), esse seria o último estágio a ser atingido onde não existiriam as fronteiras entre as disciplinas. Nunes chama a atenção para a tipologia de Bastide (1968) onde a "pesquisa integrada teórica" levaria à criação de novos métodos, novos tipos de experi- 
mentação e onde finalmente o diálogo se extinguiria em troca de uma unicidade da obra coletiva. Qual seria o exemplo para um tal grau de integração?

E como seria um projeto interdisciplinar na perspectiva habermasiana?

Para pensar tal projeto é fundamental a compreensão do conceito de entendimento ou comunicação voltada para o consenso. Essa pode ser definida basicamente como uma troca ativa e pacífica de opiniões e informações entre os participantes de uma ação ou práxis social, ou melhor, como um processo social que se dá através da linguagem, tendo como referência certas estruturas de racionalidade. A ação voltada para o entendimento ou consenso é diferente daquela orientada para o sucesso, como já observado. É importante destacar o aspecto dinâmico de entendimento que não é definido por Habermas como um consenso já obtido, mas como um processo comunicativo dirigido para a obtenção de um consenso sempre provisório e sempre renovável: Verstandingung (Habermas, 1987).

O interesse de Habermas não está especificamente nas características empíricas dos dois tipos de comportamentos - a ação teleológica voltada para o êxito e a ação comunicativa -, mas nas estruturas gerais que lhe permitam colher as condições formais de participação na ação. Ou seja, aqueles padrões que se situam na base do saber pré-teórico utilizado por falantes competentes, que percebem quando estão querendo influenciar estrategicamente a ação dos outros e quando querem entrar numa relação de comunicação voltada ao consenso.

O entendimento não pode jamais ser induzido a partir de fora, precisa ser aceito como válido pelos próprios participantes da comunicação. Além disso, os processos de entendimento que visam ao consenso, precisam satisfazer necessariamente às condições de uma aceitação racional que se dá ao conteúdo de um proferimento. Daí a possibilidade de distinguir o entendimento em relação a qualquer consenso ingênuo. Essas são algumas vantagens da primazia dada ao entendimento através da linguagem em relação a outros esquemas teóricos.

Para que essas idéias fiquem mais claras é necessário considerarmos o entendimento como um processo que engloba uma série encadeada de atos de fala. Neste contexto o ato de fala de um participante só tem êxito quando o conteúdo ou a oferta contida nesse ato for aceita por outro participante que poderá responder afirmativa ou negativamente. Tanto o primeiro falante, que levanta uma pretensão de validade, como o segundo, que reconhece ou não aceita esta pretensão, têm suas decisões apoiadas em algum tipo de razão ou argumento.

Para compreender de forma mais completa o conceito, é preciso tomar como referência o par dialético "ação comunicativa versus discurso", que consiste na contraposição entre duas formas de comunicação.

A ação comunicativa constitui-se quando os participantes aceitam, sem discutir, sem questionar, pretensões de validade que formam o consenso básico. Lembremos o conceito apresentado de forma mais completa no item acima: é importante considerar que os participantes ou atores aceitem as pretensões a partir da referência a um mundo da vida compartilhado que lhes garanta as pré-interpretações necessárias ao entendimento.

O discurso se verifica quando os participantes interrompem a ação comunicativa fluida e perfeita, para procurar argumentos capazes de fundamentar pretensões de validade. Isso acontece quando as pretensões de validade tornam-se problemáticas, questionáveis e parte do conteúdo do mundo da vida dos atores torna-se acessível à reflexão.

Poderíamos pensar na metáfora da dança. Um par dançando fluidamente ao som de uma valsa (ação comunicativa) de repente é interrompido por um problema (cessa a música, por exemplo). Surgiu um problema: inicia-se o discurso.

Observe-se que Habermas confere um sentido mais amplo ao conceito de discurso comumente utilizado na filosofia, o qual se desdobra em três dimensões básicas: (Siebeneichler e Habermas, 1989).

1) Como um pressuposto idealizado, uma situação de fala ideal levada em conta sempre que se discute pretensões de validade.

2) Como parte de um trabalho argumentativo sistemático, sob a forma de discurso, que pode ser teórico, prático ou hermenêutico.

3) O próprio trabalho filosófico em geral.

Para Habermas, quando as pessoas falam, quando trocam entre si atos de fala, têm que apoiar-se necessariamente num consenso que serve como pano de fundo para a ação comunicativa. Esse consenso é explicitado através do reconhecimento recíproco antecipado, de 
pelo menos, quatro pretensões de validade que correspondem aos quatro tipos de atos de fala chamados de universais constitutivos do diálogo ou universais pragmáticos (Siebeneichler, 1989):

a) a pretensão de inteligibilidade da mensagem contida nos proferimentos comunicativos;

b) a pretensão de verdade do conteúdo propositivo dos proferimentos relacionados ao mundo objetivo, que se realizam através dos atos de fala constatativos;

c) a pretensão de correção, validade ou de legitimidade do conteúdo normativo e valorativo da mensagem contida nos proferimentos que se referem ao mundo social e se realizam através dos atos de fala regulativos e valorativos;

d) a pretensão de sinceridade e autenticidade dos proferimentos relacionados ao mundo subjetivo e que se realizam através dos atos de fala expressivos.

Em todo ato de fala razoável exigimos necessariamente a verdade do conteúdo afirmado no proferimento, a sinceridade da intenção manifestada nele, bem como a correção do pano de fundo normativo que acompanha a relação interpessoal que se estabelece nesse ato de fala (Siebeneichler e Habermas, 1989).

Apesar da especialização lingüística representada em cada tipo de discurso, nenhum deles pode abstrair totalmente das outras pretensões de validade. Assim, os tipos puros de atos de fala são idealizações. Na realidade, estes assumem formas mistas, ainda que no nível do discurso se possa identificar o predomínio de algumas formas puras (Habermas, 1987 in Rivera, 1995).

O discurso resulta no resgate das pretensões de validade e assume a forma de discurso teórico quando se refere às pretensões de verdade do conteúdo propositivo dos proferimentos cognitivos referentes ao mundo objetivo e a forma de discurso prático quando se propõe a resgatar pretensões de correção das normas que regulam a ação social.

O discurso teórico visa à superação racional, progressiva e argumentativa de conceitos e de linguagem inadequadas. Quatro passos fazem parte desse processo.

1) Interrupção da ação e início do discurso.

2) Explicação teórica da questão problematizada através de argumentos escolhidos dentro de um determinado sistema de linguagem.

3) Nível do discurso metateórico quando é necessário passar para sistemas de linguagem alternativos.
4) Nível da auto-reflexão do sujeito agente e modificações sistemáticas das linguagens de fundamentação. Aqui rompe-se o discurso teórico e passa-se ao nível de questionamento do que pode valer ou não como conhecimento. Corresponde a uma reflexão prática e a uma tematização dos diferentes interesses extrateóricos que condicionam o conhecimento: controle da natureza, comunicação, emancipação. Segundo Habermas (1973), citado por Rouanet (1986) apud Rivera (1995): Na reconstrução do progresso do conhecimento, as normas teóricas fundamentais desnudam seu cerne prático: o conhecimento mede-se tanto com referência à coisa, como com referência ao interesse, que o conceito de coisa deve levar em conta.

O discurso prático é o meio pelo qual se pode examinar a pretensão de correção de normas e valores e tem por objetivo também uma auto-reflexão do sujeito. Compreende também quatro passos, sendo que o último constitui a construção de um acordo sobre o modo de interpretar as necessidades à luz de informações do que seria realizável no futuro o que significa tomar como referência a antecipação de uma verdade possível, de uma vida justa e emancipada. Esse acordo ou consenso só será verdadeiro se for baseado nessa antecipação e por sua vez essa antecipação deve ser baseada num consenso (Siebeneichler e Habermas, 1989).

Rompem-se os limites do discurso prático porque a questão prática sobre o tipo de conhecimento que deveríamos querer ... depende claramente da questão teórica sobre o tipo de conhecimento que podemos querer (Habermas, 1973 apud Rouanet, 1986 apud Rivera, 1995).

Ou seja, Habermas prevê uma passagem regulada de um tipo de discurso a outro. É importante destacar que Habermas não aceita a separação rígida entre o mundo da natureza (mundo objetivo) e o mundo dos costumes (mundo social), e que, ao romper com a filosofia da consciência ou do sujeito e partir para a nova moldura do paradigma comunicativo, fatos e normas podem ter o mesmo tratamento no discurso, no sentido de que podem ser fundamentados. Verdade, legitimidade e veracidade são os três aspectos presentes em qualquer ato comunicativo e inseparavelmente ligados a ele e constituem os três critérios de validade que podem ser questionados através do discurso teórico ou prático.

A inseparabilidade entre questões técnicas e práticas é reforçada por Rivera (1995) quando desenvolve uma discussão sobre o modelo 
de decisão pragmatista de Habermas (1987), que, apoiado em Dewey, assinala que existe uma relação dinâmica, recíproca e crítica ao longo da história entre valores e técnicas. Novas técnicas podem tornar obsoletos ou inoperantes valores tradicionais, contribuindo para o surgimento de novos valores, assim como os valores podem sustentar o desenvolvimento de novas técnicas.

Essa relação crítica entre valores e técnicas estaria na base da proposta de um diálogo crítico entre cientistas e políticos, que deve considerar os interesses sociais e ser orientado por um determinado mundo social da vida, ou seja, mediado pela opinião publica.

Outro conceito relevante é o de situação de fala ideal que tem como referência a idéia de um consenso ideal que nunca será atingido na prática e supõe-se que não exista qualquer elemento de coação a não ser a do melhor argumento. As condições contrafáticas dessa situação ideal são as condições de toda a interação realizada através da linguagem. $\mathrm{O}$ autor as explicita através dos universais pragmáticos ou da chamada Pragmática Universal desenvolvida por ele (Siebeneichler, 1989):

a) A igualdade de chances na utilização do discurso teórico o que garante que qualquer opinião pode vir a ser tematizada e sofrer críticas.

b) O emprego simétrico de atos de fala regulativos que podem impedir normas que coagem.

c) A oportunidade igual de chances no uso de atos de fala representativos garante a reciprocidade nas colocações subjetivas.

Nessas condições contrafáticas estão presentes as idéias de verdade, liberdade, justiça e reciprocidade que se expressam de formas distintas em diferentes épocas ou contextos culturais.

Finalmente, para pensarmos o projeto interdisciplinar segundo Habermas faz-se necessário abordarmos a crítica da filosofia ou teoria crítica. Essa crítica é exercida em dois planos convergentes: a crítica "quase transcendental”, formal e pragmática, a qual traduz em sua estrutura o interesse em emancipação e comunicação e a "crítica quase-empírica", de uma teoria da sociedade, ou teoria da modernização social que busca os vestígios da razão comunicativa na história. Ao contrário da filosofia transcendental, que exercia um papel de “tribunal da razão", como queria Kant, a filosofia crítica passa a ocupar um papel de me- diadora entre o mundo da vida e as esferas dos experts nas ciências, o papel de intérprete hermenêutico, buscando resgatar a pretensão de unidade e universalidade dos diferentes fragmentos teóricos isolados nos diferentes mundos - objetivo, social e subjetivo - através de uma cooperação entre as ciências. $O$ único critério de verdade passa a ser o da plausibilidade e da coerência possível entre os distintos fragmentos teóricos, alcançada através do consenso atingido por um grupo de cientistas ou pela comunidade científica de forma mais ampla. De acordo com o falibilismo popperiano, aceito por Habermas, as ciências não necessitam de uma fundamentação transcendental do saber mas de um consenso sobre sua especificidade e sua aplicabilidade na vida prática. As ciências não encarnam a verdade - como no positivismo - mas representam certas pretensões de validade que necessitam ser discutidas e resgatadas à luz de um consenso ideal.

Apresentados e discutidos os principais elementos do projeto "interdisciplinar comunicativo" habermasiano, retomaremos a síntese dos pressupostos dessa proposta realizada por Minayo (1991).

1) O pressuposto de que a ciência não possui uma fundamentação transcendental e infalivel conduz ao caminho da construção do conhecimento através de um processo racional de entendimento dos diferentes saberes e sua relação com o mundo da vida.

É necessário considerarmos que o acesso ao mundo da vida, que nos fornece as pré-interpretações necessárias ao entendimento, não nos é dado explicitamente. Apenas quando aparece um problema, uma questão a ser tematizada, um desafio, é que temos acesso a parte desse saber implícito. Nesse momento "desmorona" o mundo da vida, fracassam nossas certezas; encontramo-nos diante de uma crise (pessoal, moral, de paradigmas) e somos obrigados a interromper o discurso normal e assumir uma postura crítica diante da tradição, da ideologia etc., o que leva à possibilidade de desmascaramento de estados de comunicação sistematicamente distorcidos. Construído o novo consenso, esse conteúdo retorna ao mundo da vida dos atores e atuará como pressuposto ou saber implícito para novas ações.

2) As ciências abstratas e a filosofia têm que entrar em entendimento com as ciências empiricas, buscando criticar e avaliar os pressupostos gerais de determinado saber através do discurso argumentativo relacionado às descober- 
tas obtidas, à questão ética e à subjetividade. A proposta interdisciplinar se expressaria através da exposição do trabalho científico às muitas vozes da razão em busca de sua unidade, o que requer, por um lado, reconhecimento dos limites dos pesquisadores, das disciplinas e do próprio campo do conhecimento e, por outro lado, um diálogo crítico que articule o trânsito das diferentes linguagens e aponte o rumo de um "humanismo radical" como fim de todo conhecimento.

De fato, é através do discurso, nas formas já discutidas anteriormente, que se pode exercer a suspeição crítica das pretensões de validade levantadas pelas distintas ciências.

Em Unidade da razão na multiplicidade de suas vozes, Habermas (1989) dialoga com Lyotard, chegando ao final, a discordar de seu relativismo ou contextualismo radical. Questiona também o contextualismo mitigado de Rorty e Putnam. O autor defende a idéia de uma unidade da razão que somente continua perceptível na pluralidade de suas vozes - como a possibilidade da passagem compreensivel, por mais ocasional que seja, de uma linguagem para outra. Esta possibilidade da comunicação voltada para o consenso, realizada transitoriamente e assegurada apenas de modo procedural constitui o pano de fundo da pluralidade de tudo o que nos cerca hoje... Em outras palavras, ao invés do relativismo total, da ausência de parâmetros, referências ou normas universais, Habermas aponta um caminho capaz de resgatar uma unidade, ainda que através da multiplicidade. Um caminho capaz de nos propor a possibilidade de universalização de alguns conceitos e normas, através da obtenção de um consenso, ainda que provisório.

Para o autor a razão é um conceito processual e que, apesar de surgir a partir de fragmentos e de ser contingencial, mantém sua unidade porque se constitui através do meio lingüístico, ou melhor, da comunicação lingüística voltada ao consenso. É a razão comunicativa, ou ação comunicativa que permite a compreensão não só de fatos do mundo objetivo, mas das normas sob as quais agimos e da noção de subjetividade o que possibilita a construção de uma proposta interdisciplinar que resgate o interesse na emancipação do homem - humanismo radical -, o qual pressupõe o entrelaçamento não hierarquizado e dialético entre a filosofia e as ciências, gerando um fecundo clima de crítica recíproca.

3) A teoria da racionalidade interdisciplinar de Habermas está referida incondicional- mente às estruturas do mundo cotidiano (mundo da vida) onde se articulam os produtos da ciência e da técnica como cultura, esta no seu sentido mais amplo, a linguagem comum, onde os problemas do mundo contemporâneo são vivenciados por todos nós.

Para Habermas, por mais especializada que seja a linguagem das ciências é necessária a utilização da moldura da linguagem comum para que sejam divulgadas e compreendidas. Portanto, mesmo os cientistas ou a comunidade científica estão referidos ao mundo da vida que fornece "pano de fundo" de toda a compreensão articulada lingüisticamente, inclusive a compreensão da própria ciência. É aqui que reside a possibilidade de construção de um projeto interdisciplinar.

\section{Interdisciplinaridade e saúde: o exemplo do planejamento estratégico situacional e o caso da AIDS}

A perspectiva do projeto interdisciplinar de Habermas nos parece bastante profícua com relação à possibilidade de "costurar" as diversas racionalidades presentes no planejamento em saúde, tanto no que diz respeito aos aspectos discutidos por Rivera (1995) - a racionalidade econômica, política e burocrática, como àquelas dimensões da racionalidade apresentadas por Habermas em sua teoria da ação comunicativa: teleológica/estratégica, normativa (referente à normas), subjetiva e comunicativa - esta última como articuladora das demais.

Em trabalho anterior (Artmann, 1993), discutimos a partir do paradigma comunicativo (da intersubjetividade) os aspectos estritamente estratégicos e os aspectos comunicativos presentes no enfoque de planejamento estratégico situacional (PES) de Carlos Matus.

O que queremos destacar aqui é apenas um aspecto: o da explicação situacional discutida também por Rivera (1995), o que nos permitirá trabalhar a perspectiva interdisciplinar habermasiana.

Antes, contudo, consideramos importante destacar que Matus (1987) afirma no capítulo intitulado "Planificación, un problema entre los hombres”, que os homens, na vida prática, não dividem a realidade em disciplinas estanques, mas a vêem sob a forma de problemas que devem ser enfrentados e os quais os motivam para a ação. As categorias-proble- 
mas, por um lado, como articuladoras das várias dimensões da realidade, e ator, por outro, como sujeito social, homem de ação, força/organização social (ator coletivo), permeiam toda a obra do autor, a qual não poderia ser apreendida sem considerá-las, segundo nossa compreensão.

Matus é um autor que dialoga com vários outros, com distintas correntes de pensamento de diferentes disciplinas. Para a discussão da interdisciplinaridade, podemos considerar duas perspectivas: a teórica (ou da construção do enfoque) e a prática, ou seja, a aplicação numa situação concreta.

Do ponto de vista teórico, consideramos o PES um enfoque interdisciplinar bem-sucedido e exemplificamos esta afirmação com o conceito de situação. As bases do conceito de situação encontram-se em vários autores, sejam ele representantes da fenomenologia, do marxismo ou da teoria da ação, como por exemplo Heidegger, Gadamer, Ortega e Gasset, Kosik, Husserl etc. cuja contribuição se evidencia em diversos pontos, como a distinção entre realidade e verdade, a auto-referência do ator, sua visão de mundo, motivação subjetiva e intuição na apreensão da realidade; a concepção da realidade como espaço conflitivo, onde atuam várias forças sociais ou atores com projetos diferenciados, a necessidade de explicação rigorosa através da consideração da realidade ao nível essencial, para além das aparências, entre outras.

Em Política y plan (1982), Matus sintetiza o conceito de situação, considerando-o como sinônimo da explicação situacional, através das seguintes características:

a) Auto-referencial: a explicação não é única ou objetiva, mas referida ao ator que a explica, em função de sua visão de mundo, valores, ideologia, posição que ocupa na sociedade e em função de seu projeto político de ação;

b) Dinâmica: porque se refere ao movimento da realidade e busca articular passado, presente e futuro, analisando as causas e processos que geraram a situação problemática (passado), como se manifesta hoje o problema (presente) e as tendências que se delineiam no futuro para desenhar a intervenção mais adequada;

c) Policêntrica: característica complementar à primeira que significa levar em conta a explicação dos outros atores sobre a realidade, já que nela coexistem outros capazes de planejamento e ação, sejam eles oponentes ou possíveis aliados e que controlam sempre parte dos recursos necessários à intervenção;

d) Totalizante: na medida em que articula as várias dimensões da realidade (econômica, política, ideológica, cultural etc.), o que não significa uma explicação total que esgota todas as possibilidades. A explicação é sempre um "recorte" problemático, que seleciona as causas relevantes levando em consideração as várias dimensões apontadas;

e) Rigorosa: porque visa atingir a essência, as "leis básicas", para além dos fenômenos ou fatos mais superficiais da realidade. Para tanto é necessário um modelo teórico de leitura da realidade; no caso de Matus, a Teoria da Produção Social, que concebe a realidade em três níveis: o nível dos fatos, o das acumulações e o das regras ou leis básicas, os quais se articulam entre si;

f) Ativa: porque a explicação fundamenta a ação do ator; não se constitui numa abordagem teórica ou de pesquisa, está sempre voltada para a intervenção;

g) Adaptável: embora seu caráter totalizante, adapta-se a situações nacionais, regionais, locais ou setoriais (setor saúde; por exemplo), considerando-se aqui os vários espaços de governabilidade onde atuam as diversas forças sociais.

Para nossa discussão interessa-nos destacar principalmente o policentrismo do conceito de situação que diferencia radicalmente a explicação de uma realidade problemática de saúde por exemplo, do diagnóstico tradicional, monológico e "objetivo", construído muitas vezes apenas com o objetivo de estudar os problemas sem a preocupação de intervir. Isso não significa que um estudo dessa natureza não possa ser aproveitado como parte das informações na construção da apreciação situacional, esta sim, voltada essencialmente para a intervenção.

Matus (1987) considera a apreciação situacional um diálogo entre um ator e outros atores, cujo relato é assumido por um dos atores (ator-eixo ou principal), consciente do contexto situacional que o faz coexistir numa realidade conflitiva que admite outros relatos.

Essa afirmação pode ser interpretada tanto do ponto de vista estratégico da ação ( $R$ ivera, 1995), como a partir da perspectiva comunicativa (Artmann, 1993). No primeiro caso, o componente instrumental do policentrismo predomina, na medida em que o ator principal apenas pretende complementar sua explicação considerando a referência dos ou- 
tros atores, para, em última instância, aumentar a eficácia de seu plano, agindo estrategicamente e buscando diminuir e controlar o campo de ação dos outros atores. De fato, em outro momento de sua proposta - ao discutir o momento estratégico -, Matus sugere exatamente esse tipo de ação com relação aos oponentes. Além do sentido estratégico referido, a explicação policêntrica permite a complementação da apreciação auto-referente.

Matus exemplifica essa questão com o problema da marginalidade social cujas causas podem ser explicadas por determinado ator como decorrentes das relações de propriedade dos meios de produção e pelos valores individualistas gerados pelo sistema capitalista e por outro ator como decorrentes da falta de educação, preguiça e desmotivação da população. As duas maneiras de explicar levariam a diferentes formas de intervenção, com distintos níveis de eficácia que dependeriam, em parte, da maior ou menor capacidade explicativa das teorias de base utilizadas. Ainda que Matus defenda uma maior potência para a primeira explicação, afirma que a segunda não é completamente falha, podendo ser integrada de forma subordinada à primeira.

A interpretação comunicativa do policentrismo na explicação situacional estaria representada pela possibilidade de um diálogo aberto entre vários atores que explicitam suas posições e constróem cooperativamente seus planos de ação. É importante lembrar aqui que Matus considera o valor que a população dá ao problema como critério fundamental e imprescindível no protocolo de seleção dos problemas a serem processados. $\mathrm{Na}$ análise de algumas experiências concretas de aplicação do enfoque temos observado pelo menos duas formas em que a população (que só se constitui um ator quando está organizada) estaria presente: 1) através de representantes de movimentos populares/sociais (por exemplo, conselhos de saúde) e 2) a consideração pelo ator principal da posição da população através da tentativa do "colocar-se em situação". Nas inúmeras adaptações das quais se tem conhecimento, há casos em que se desconsidera totalmente a posição da população, o que para nós, constitui uma grave distorção do enfoque, embora continuem sendo referidas como experiências de adaptação do PES.

Destacamos esse aspecto porque, na proposta interdisciplinar habermasiana, um ponto fundamental constitui-se no resgate dos conteúdos utópicos da história da humanidade, ou seja, dos conteúdos de solidariedade e emancipação, os quais, para o autor, encontram-se embutidos na linguagem. Para ele, a ética do ponto de vista do discurso prático considera que a solidariedade, a justiça e o bem-estar correspondem a representações fundamentais que podemos reduzir às condições de simetria e expectativas de reciprocidade presentes na práxis comunicativa normal, voltada ao entendimento.

Ora, a consideração do que é importante para a população, na proposta do PES, nos remete justamente à idéia do bem comum, da solidariedade, ou seja, a uma aproximação daqueles conteúdos utópicos presentes em Habermas. Este é um dos aspectos que consideramos "comunicativos" na proposta matusiana e que não pode ser preterido, sob o risco de grave distorção da proposta, como já afirmado. O PES foi idealizado como um método de planejamento do público no contexto latinoamericano, considerando a população como variável imprescindível.

O policentrismo juntamente com a característica totalizante que leva em conta as várias dimensões da realidade pode se expressar através da consideração das distintas explicações sobre a realidade proporcionadas pelas diferentes disciplinas científicas. Matus (1987) propõe também a passagem da linguagem especializada do PES para a linguagem comum na construção e apresentação dos planos de ação.

É importante destacar ainda, que a análise de contextos de ação comunicativos ou estratégicos pode ser mais complexa do que parece à primeira vista na medida em que o próprio Habermas (TAC, 1987) nos lembra que uma mesma ação pode ser considerada comunicativa ou estratégica. Por exemplo, tomando como foco de análise o interior de uma mesma força social, os atores podem estar agindo comunicativamente. Essa mesma ação pode se tornar estratégica com relação aos oponentes (Artmann, 1993).

Do ponto de vista prático, um projeto interdisciplinar teria que ser analisado também a partir de conseqüências práticas, as quais só poderiam ser medidas concretamente com o passar do tempo, retrospectivamente, ou a partir de uma antecipação das conseqüências realizada argumentativamente, bem como através da consideração dos procedimentos utilizados. Não nos propomos neste trabalho a desenvolver um "caso", mas vale a pena fazermos uma 
tentativa de discutir um problema concreto e sua possível explicação situacional hipotética.

Tomamos o problema do aumento da morbidade por AIDS no contexto de um município médio (300.000 habitantes) em início de gestão e que deve concluir seu Plano Municipal de Saúde. O ator principal seria o secretário municipal de saúde. Outros atores: diretor do hospital " $X$ " que atende aidéticos da região (cerca de 12 municípios menores); o presidente do Conselho de Saúde; médicos e funcionários da secretaria e de outras unidades de saúde.

A população representada pelo presidente do Conselho de Saúde se posiciona a favor do enfrentamento do problema, principalmente pelo medo do alastramento da doença, ainda que acrescente junto a esta, várias outras prioridades. Todos concordam que a AIDS é um problema que só pode ser explicado pela via interdisciplinar e cujas propostas de intervenção também devem se dar nesse nível.

Simplificaremos a explicação através de uma lista de causas e conseqüências.

\section{Causas biológicas}

- existência do vírus e sua capacidade de multiplicação e adaptação

\section{Causas médico-tecnológicas}

- maior eficiência na detecção do vírus (maior número de testes e formas de diagnóstico)

- aumento dos índices de contaminação do sangue

- privatização do sangue

- política ineficiente de controle dos bancos de sangue

- conhecimento incompleto sobre a imunidade humana

\section{Causas sociais, culturais e políticas}

- liberalização dos hábitos sexuais

- prostituição

- educação em saúde precária

- prevenção deficiente

- aumento do consumo de tóxicos

- ausência/deficiência de uma política de proteção/prevenção da toxicomania

- problemas de desagregação familiar e frustração de expectativas sociais

- alto nível de preconceito que reforça a desinformação

\section{Causas econômicas}

- mercado de trabalho excludente - aumento do índice de desemprego (que pode levar ao aumento de consumo de drogas e à desagregação familiar)

- privatização da saúde

- alto custo dos medicamentos no tratamento

- interesses econômicos dos laboratórios e empresas fabricantes de medicamentos

As diversas causas se relacionam entre si e constituem uma rede hierarquizada, onde algumas se situam apenas no nível fenomênico ou dos fatos, algumas no nível intermediário das acumulações e que seriam capazes de produzir novos fatos e outras, mais determinantes ou essenciais, no nível das regras básicas, como por exemplo, as questões culturais.

Uma pré-análise de governabilidade e viabilidade nos leva a perceber que este é um problema que extrapola o espaço municipal, devendo necessariamente ser analisado em um espaço mais amplo.

O exemplo da AIDS é interessante por envolver tanto questões relacionadas ao mundo objetivo, quanto referências ao mundo normativo e ao subjetivo que representa uma problematização ou tematização ampla que podemos chamar, na linguagem habermasiana, de um "desmoronamento" do mundo vital ou dos saberes de base que sustentam nossa compreensão do mundo e nossa ação.

Com relação às questões objetivas temos hoje, por exemplo, desafios cognitivos e tecnológicos diante da perda da potência explicativa das teorias que sustentaram até agora o saber sobre o desenvolvimento das doenças infecciosas (transmissão/reprodução do vírus, funcionamento do sistema imunológico humano etc.) cujas pretensões de validade científica passam por um amplo questionamento.

A dimensão ética está fortemente presente em algumas discussões, como por exemplo: a possibilidade/oportunidade de disponibilizar gratuitamente remédios caros, num contexto de crise, quando existem vários outros problemas de saúde da população a serem enfrentados; o problema ético com relação a tornar público ou não o diagnóstico de AIDS: por um lado entra a questão de proteção ou privacidade individual (o doente pode não querer que sua situação seja conhecida por causa da segregação social) e, por outro lado, a proteção da comunidade; o próprio problema da 
segregação e do preconceito contra os doentes, que fere a ética da solidariedade.

É necessário considerar também um contexto ético/cultural que coloca em questão normas, valores e comportamentos não apenas relacionados à doença em si, mas igualmente hábitos e padrões referentes a outras dimensões (comportamentos sexuais, relação entre parceiros etc.).

É importante destacarmos a inter-relação entre essas várias dimensões (ética, técnica, política) como aponta Habermas, apoiado em Dewey. No caso da AIDS podemos considerar, por exemplo, que na medida em que se avance na descoberta e fabricação de medicamentos capazes de controlar a doença, parte da questão ética se ameniza porque a segregação diminui. O próprio avanço da técnica pode tornar determinados valores cultivados sobre a AIDS obsoletos e ultrapassados.

Por outro lado, uma ênfase da atuação sobre a dimensão social, a marginalidade, a prevenção no caso dos toxicômanos, o controle e prevenção de outras formas de transmissão, como sangue, por exemplo, poderá reduzir a morbidade e diminuir a necessidade de intervenções técnicas do tipo medicamentosa e de hospitalização. O investimento em tecnologia pode levar à queda do preço dos medicamentos.

De qualquer forma, no nível do planejamento, seja no espaço municipal ou local, ou em outros mais amplos, exige-se propostas de ação concretas que articulem as várias áreas (educação, prevenção, informação, atendimento médico-hospitalar, assistência psicossocial etc.), as quais devem ser atualizadas na medida dos avanços científicos e na incorporação de propostas advindas dos movimentos sociais.

\section{Considerações finais}

A discussão sobre a AIDS encontra-se, em geral, ainda no nível que Japiassu chama de multidisciplinaridade, com exceção, talvez, de alguns projetos ainda muito incipientes. Faz-se necessário ampliar essa discussão em direção a um contexto discursivo teórico/prático democrático, envolvendo, de forma a mais ampla possível, o círculo de cientistas e o círculo dos destinatários das técnicas e das normas existentes e virtuais.

Essa possibilidade não está dada automaticamente, mas depende da vontade e atuação concreta dos atores envolvidos e interessados.
Para finalizar, retomamos e destacamos alguns aspectos centrais da fundamentação do projeto interdisciplinar de Habermas:

a) o papel assumido pela linguagem como articuladora da ação em geral e de todas as formas de saber ligadas à atuação sobre o mundo considerado em seu conceito tríplice ampliado e em relação ao mundo vital;

b) a possibilidade de uma passagem regulada de um tipo de discurso a outro, que torna muitas vezes tênues as fronteiras entre questões teóricas e práticas;

c) a simultaneidade das várias pretensões de validade em todo ato de fala, ou seja, a presença, em cada domínio lingüístico especializado das outras pretensões de validade, além da dominante. Quando os cientistas discutem sobre a verdade de um fato científico, por exemplo, estão necessariamente presentes também outros interesses, sociais, subjetivos, bem como normas e valores do contexto cultural e historicamente determinado;

d) a inseparabilidade histórica entre valores e técnicas, sugerindo um diálogo crítico no nível da tomada de decisão - entre cientistas e políticos, mediado pela opinião pública. Como afirma Minayo (1991), a interdisciplinaridade é um tema acadêmico que "transborda das salas de aula e dos laboratórios de pesquisa para os gabinetes do poder" e ainda, de forma prática, para o dia-a-dia dos cidadãos;

e) o papel assumido pela filosofia, de guardiã da ligação necessária entre a opinião pública e os experts. A preocupação com os momentos de diferenciação e ao mesmo tempo o resgate dos núcleos de integração entre as ciências e entre esta esfera e a da moral e da arte.

No planejamento situacional encontramos um "correlato" de um diálogo crítico interdisciplinar na idéia de explicação situacional, como uma explicação dominada em maior ou menor intensidade por várias racionalidades. O policentrismo situacional corresponde à proposta de um processo amplo de comunicação a serviço da elaboração dos planos de ação. A necessidade de um diálogo crítico entre as várias especialidades e formas de cálculo faz parte essencial do conceito de situação.

E, por último, queremos enfatizar que, para além do cálculo estratégico, visando ao êxito do plano de um ator, é necessário resgatar e valorizar os processos de busca de entendimento na articulação de planos de ação que considerem os conteúdos utópicos que fazem parte do interesse humano, os quais, na área 
de saúde, deveriam se traduzir, concretamente, na melhoria das condições de saúde da população como um todo.

\section{Referências bibliográficas}

Artmann E 1993. O planejamento estratégico situacional: a trilogia matusiana e uma proposta para o nível local de saúde (uma abordagem comunicativa). Dissertação de mestrado, ENSP, Rio de Janeiro.

Bastide R 1968. Approche interdisciplinaire de la maladie mental, pp. 435-449. In The social sciences. Problems and orientations. Mouton-Unesco, Paris.

Habermas J 1987. Teoria de la acción comunicativa. Taurus-Biblioteca de Filosofia Contemporânea, Ed. 70, Madri-Portugal.

Herrero X 1987. Racionalidade comunicativa e modernidade. Revista Sintese 37, 1.

Japiassu H 1976. Interdisciplinaridade e patologia do saber. Imago, Rio de Janeiro.

Matus C 1987. Politica, planificación y gobierno. Borrador, Washington.

Matus C 1982. Política y plan. lveplan, Venezuela.

Minayo MCS 1991. Interdisciplinaridade: uma questão que atravessa o saber, o poder e o mundo vivido. Medicina, 24 (2), abr./jun.

Nunes EV 1995. A questão da interdisciplinaridade no estudo da saúde coletiva. In Canesqui AM (org.). Dilemas e desafios das ciências sociais na saúde coletiva. Hucitec-Abrasco, São Paulo-Rio de Janeiro.

Popper K 1975. O conhecimento objetivo. Itatiaia, São Paulo.

Rivera FJU 1995 Agir comunicativo e planejamento social (uma crítica ao enfoque estratégico). Fiocruz, Rio de Janeiro.

Rouanet SP 1986. Teoria crítica e psicanálise. Biblioteca Tempo Universitário, Rio de Janeiro. Apud Rivera (1995).

Siebeneichler FB e Habermas J 1989 Razão comunicativa e emancipação. Tempo Brasileiro, Rio de Janeiro.

Siebeneichler FB 1989 Encontros e desencontros no caminho da interdisciplinaridade: G. Gusdorf e J. Habermas. In Revista Tempo Brasileiro 98, jul./set. 